an oscillating valve, and a free pendulum (Mr. F. Hope Jones) which swings in vacuo and spends only $2 \mathrm{ft}$. oz. of energy per week. Measurements of pressure and temperature are respectively exemplified by some Pirani pressure gauges (General Electric Co., Ltd.), depending on the cooling of a hot wire by the gas under measurement, and by a resistance thermometer, thermocouples, and a disappearing-filament pyrometer (N.P.L.). This section of the exhibition is supplemented by the N.P.L. exhibit in the Palace of Engineering.

Considerable space is devoted to metallurgy. Specimens of crystallised gold are shown by Prof. A. Liversidge, and there are interesting studies of the behaviour under stress of very large single crystal specimens of aluminium (Prof. H. C. H. Carpenter, Prof. G. I. Taylor, and Miss C. F. Elam), and of tungsten (Dr. F. S. Goucher, General Electric Co., Ltd.), the deformation produced by stress being of the nature of a shear or slip in a direction parallel to the crystal planes indicated by $\mathrm{X}$-ray analysis. A photomicrographic investigation of fatigue in other metals (N.P.L.) tends to the same conclusion. The study of alloys is exemplified by the crystal models referred to above, by a kind of threedimensional graph (N.P.L.) showing the constitution of a three-element system at various temperatures, and by diagrams, photographs, and sections illustrating the metallography of copper-tin alloys (Mr. C. T. Heycock and the late Mr. F. H. Neville).

Relics of great historical interest have been contributed by the Science Museum, the Royal Institution, and King's College, and to these must be added a representation of the coat-of-arms of the Royal Society and a volume containing facsimiles of the signatures in the latter's charter book.

For the sciences grouped under the heading of geophysics, which are characterised by their all being dependent on observations made simultaneously by a number of observers distributed over the earth's surface, an exhibition is being held in one of the new galleries of the Science Museum at South Kensington, and portions of this will be moved to the Wembley Exhibition in rotation. This method of compensating for the scantiness of the available space was a happy thought, and no doubt many visitors will make an opportunity of seeing the whole exhibition at South Kensington, for British workers have made great contributions to these studies and their Imperial aspect is obvious : they have, moreover, a very direct bearing on everyday life. Sir Napier Shaw is responsible for a series of exhibits showing the manner in which data as to atmospheric movements and changes are obtained and collated, and (in conjunction with Miss E. E. Austin) for maps indicating rainfall and evaporation throughout the world. Capt. C. J. P. Cave contributes cloud photographs which define admirably the technical terms used by meteorologists in this connexion.

$A$ topic of urgent social importance is raised by Dr. J. S. Owens's apparatus for measuring atmospheric pollution, comprising a standard gauge for dustdeposit, an automatic intermittently acting recorder for suspended matter, and a photometer for measuring the obstruction of light by dust. Terrestrial magnetism and atmospheric electricity are illustrated by maps, records, and instruments (Dr. C. Chree and Mr. C. S. Wright), the Milne-Shaw seismograph and some seismological maps are shown by Prof. H. H. Turner and Mr. J. J. Shaw, and Col. H. G. Lyons and Col. H. S. L. Winterbotham are responsible for a study of the progress made in the mapping of the Empire. It is surprising to learn that after the immense amount of work already accomplished in the latter connexion, two-thirds of the Empire has been only roughly mapped and one-fifth has not been mapped at all. This exhibit is supplemented by some photographs taken during the climbing of Mount Everest, a scale model of which, to be found in the Government Building, is to register the progress of the third expedition as reports are received.

\title{
Obituary.
}

\section{Mr. Kenneth J. J. Mackenzie.}

$\mathrm{B}$ the death of Kenneth James Joseph Mackenzie, which occurred in a nursing home in London on June 5 after a prolonged illness, the University of Cambridge has lost an outstanding personality and the agricultural world a man of distinguished eminence. $\mathrm{He}$ was the son of Major A. C. C. Mackenzie, and was born at St. Helena on May $\mathrm{x}, \mathrm{x} 867$. He was educated at Fort Augustus College, the Agricultural College, Wye, the British Dairy Farmers' Institution, Reading, and abroad. He afterwards became professor of agriculture at Wye.

In $\mathrm{I}_{907}$, when the School of Agriculture at Cambridge was in process of rapid development, Mackenzie joined the teaching staff and became director of the University farm; very soon after, he was appointed University lecturer. He added greatly to the strength of the School, and by his highly attractive and stimulating teaching acquired a great influence which was spread widely by his many students, not only in Great Britain but also throughout most parts of the world. Mackenzie joined Christ's College, where he was always very welcome at the high table and in the Combination room. He received the honorary degree of M.A. from the University, and in I9I4 was elected reader in agriculture. He afterwards became consultant to the Institute of Animal Nutrition. He was a Governor of the Royal Agricultural Society and a constant attendant at the "Royal" Shows, and was at one time editor of the Society's Journal. His services were greatly in request as a judge, for he was an acknowledged authority on most classes of stock, and particularly cattle and pigs. He represented the British Government at the Brussels Exhibition in r9ro. During the War he went to France on behalf of the War Office and the Y.M.C.A., to lecture to the troops on the home food supply. He also took a prominent part in assisting the Government in the then difficult problem of food production.

Mackenzie's published writings include a constructive work on "Cattle and the Future of Beef-Production in England," and numerous papers, on certain aspects of bacon-curing, on milch cows and the production of store stock, on economic cattle-rearing, and on the "mutton-points" of sheep. It was always one of his aspirations to introduce into Great Britain the methods

No. 285 I, voL. I I 3 ] 
of the "Zootechnie" as carried out in France, Belgium, and Holland, to which countries he had paid many extended visits. "Zootechnie" may be described as the scientific study of domestic animals in every aspect, and more particularly in relation to agricultural practice. Within this sphere, he had done much useful work, and one of his latest papers was on the points of the ideal bacon pig, read before the Farmers' Federation at Cambridge in May of last year.

It was probably as a teacher, however, that Mackenzie was greatest. Many instructors in agriculture have been content to teach their subject according to the traditional methods of the text-books. Mackenzie, however, was never satisfied with second-hand knowledge, but spent all his available time and much of his available cash in seeking, and, so far as was in his power, in obtaining, a direct personal experience of every phase of agriculture, from bacon factories in Wiltshire and Essex to mountain sheep breeding in Wales and Scotland, and from the small holdings of Belgium and Holland to the extensive farming of Australia. This characteristic, combined with his vivid personality, was probably the main secret of his success.

About Mackenzie's activities as a lifelong Catholic, this is not the place to speak in detail. Suffice it to say that he was president of the Cambridge University Catholic Association and an active member of the Universities' Catholic Education Board. He took a leading part in the corporate life of the Catholic community in Cambridge, and he ever showed a deep devotion to the faith of his forefathers. He was a bachelor and a man of many friends. Throughout his repeated illnesses he preserved a calm and cheerful demeanour which was an impressive example to all who saw him.

F. H. A. Marshall.

\section{Sir Asutosh MoOKerJee.}

THE death of Sir Asutosh Mookerjee on May 25, shortly before attaining the age of sixty years, deprives the University of Calcutta of a leader rich in power and devotion, and scholars throughout the world of a friend. It is the extinguishing of a source from which was radiated encouragement, sympathy and inspiration to all intellectual workers of Bengal-of a beacon which showed all India the pathway to honour and greatness.

Sir Asutosh Mookerjee was until quite recently a Judge of the High Court in Calcutta and also vicechancellor of the University of Calcutta, having held the first office for close on twenty years, and the second honorary office concurrently with it for several long periods. He was an Indian who had never left India, butwas known throughout the world as an accomplished mathematician, an accomplished lawyer, an accomplished Sanskritic scholar, and above all as an apostle of culture. After winning all honours possible to a university student in Calcutta, he commenced active life as a youthful professor of mathematics ; but soon achieved that eminence as a lawyer which led to his appointment to the Tagore professorship of law, and later to the High Court Bench. He was a fellow of the Royal Society of Edinburgh, the Royal Irish Academy, and other British and foreign learned societies, president of the Asiatic Society of Bengal, r907-9, and chairman of the trustees bf the Indian Museum since 1909 .

So great were Sir Asutosh Mookerjee's working powers that his exacting professional activities seemed little more than preliminary to the manifold unselfish and gratuitous labours devoted to the welfare of his beloved University, to which he was wont to proceed daily from the High Court, and to the promotion of culture. It was his ambition that Calcutta should become a centre of learning and research; and he understood well how to inspire the enthusiasm of youth, the settled persistence of middle life, and the chastened hopes of later years, to contribute to this end. Characteristic of his capacious mind was his intimate acquaintance with the careers and personal circumstances of individual students and ex-students of the University and all concerned with or likely to be concerned with university work. The conversion of the University from a purely examining and inspecting body into a teaching institution would no doubt have been effected even without his efficient help; but the addition of numerous schools of active research was almost entirely due to his efforts.

Sir Asutosh Mookerjee was a great man because of the encyclopædic store of knowledge and information which his marvellously capacious mind contained ready for immediate use, because of his instant power of judgment and action and his clear vision of the right, and because of his power of influencing others through his intense sympathy with all strivers after truth and betterment. Every earnest intellectual worker, however humble or however eminent, would find in him a wise and understanding friend, and could talk to him as to a co-worker and an equal. Specialists in the most diverse literary and scientific subjects would find him familiar with the latest relevant literature. To every band of men engaged in the quest after truth and light his help and encouragement was freely and unselfishly given; and in learned societies and gatherings he was a dominant figure, giving appreciation where it was due and advice where it was needed. Typical of his prodigality in service were his relations to the Calcutta Mathematical Society, of which he was president from the time of its foundation at his instigation. Owing to the many other claims on his services during the week, the meetings of the Society were held on Sunday afternoons; and he never failed to be present in his presidential capacity, and to take an active part in the proceedings. He was the author of numerous papers on mathematical subjects in the publications of several learned societies.

Sir Asutosh was a dominant power in the Senate and all departments of the University of Calcutta. In troublesome debates his rising to speak almost invariably meant that the right course would be made clear and adopted. In times of open warfare with others, when his ruthless scorn of all subterfuge made compromise difficult, he fought only for the pursuit of knowledge. His death is the passing of a valiant warrior whose battle-cry was:

\section{"Let knowledge grow from more to more."}

\section{E. C.}

$$
\text { NO. } 285 \text { I, VOL. I I } 3]
$$

